\title{
Gender diversity policies in universities: a multi-perspective framework of policy measures
}

\author{
Tanya M. Timmers • Tineke M. Willemsen • Kea G. Tijdens
}

Published online: 13 October 2009

(C) The Author(s) 2009. This article is published with open access at Springerlink.com

\begin{abstract}
Are policies to increase women's share among university professors effective? The importance of gender equality on the labor market has been well established, but our understanding of what kind of policy is effective to increase the share of women is still unclear. Three sets of factors explain women's low shares at higher job levels, notably individual, cultural, and structural or institutional perspectives, and policies to increase the proportion of women therefore should address these factors. This paper aims to investigate if they do so and if they are effective. We investigated the efficacy of gender equality policy measures in all 14 universities in the Netherlands, implemented between 2000 and 2007. Based on documents and interviews, 19 measures were identified that could be classified according to the three perspectives. The university with the most measures applied four times more measures than the one with the least measures. The more measures a university applied in the cultural perspective, the more likely it also applied measures in the other two perspectives. Whereas the HR managers and policy makers at universities reported skepticism and lack of evaluations, our study reveals a positive relationship between policy measures and the reduction of the glass ceiling and between policies in the cultural perspective and the increase of the proportion of women among professors.
\end{abstract}

Keywords Women - Universities · Glass ceiling index · Implementation · Efficacy · Gender equality · Measures $\cdot$ The Netherlands

\section{Introduction}

As in other organizations, women in universities are greatly outnumbered by men in positions of formal power, authority, high status and high income. To remedy this situation, employers and HR managers often apply policy measures, like gender-neutral hiring

T. M. Timmers · K. G. Tijdens $(\bowtie)$

Erasmus University Rotterdam, Rotterdam, The Netherlands

e-mail: k.g.tijdens@uva.nl

T. M. Willemsen

Leiden University, Leiden, The Netherlands 
and selection procedures and preferential treatment of women. Given the popularity and the costs of implementing a gender equality policy, the limited information available about the variation in implementation and efficacy of policy measures is striking. As Kalev et al. (2006, p. 590) state "there has been a great deal of research on the sources of inequality, [but] there has been little on the efficacy of different programs for countering it". Our contribution is to theoretically categorize different types of gender equality policy and to examine the implementation and efficacy of these policies in universities.

Senior academics are predominantly male, in spite of a gender ratio that is closer to parity among young researchers (European Commission 2006; West and Curtis 2006). Female students outnumber male ones in higher education in European Union member states (54\% of the student population was female in 2003) and the USA (57\% was female in 2005) (European Commission 2006; OECD 2008). They complete their studies on average faster and with better results (European Commission 2008). Because of the fierce competition in the labor market, the scarcity of talented academics (Altbach 2004), and the ageing of academic staff (Enders 2001), this discrepancy results in a growing pressure on universities to attract more female academics and to increase their proportion at higher levels. Policy makers and decision makers respond to this pressure by implementing gender equality policies in their organizations (Boeckmann and Feather 2007).

The objective of the study is to investigate the efficacy of gender equality policies. Therefore, the gender equality policies of all 14 universities in the Netherlands and their impact on the proportion of female academics have been investigated. In total 19 policy measures could be categorized and for each it was studied whether they have brought about change in the share of women at higher job levels. The next section outlines the theories that try to explain gender inequality, links these theories to categories of gender equality policies and summarizes the evidence from previous studies about the effects of such policies.

\section{Theoretical framework}

The relative lack of women in higher positions is the cumulative result of multiple barriers at many points along the career path. We will briefly review theories and perspectives that explain vertical gender segregation. We follow Ragins and Sundstrom (1989) and Fagenson (1990) in distinguishing three sets of factors to explain women's underrepresentation at higher job levels: (1) individual, (2) cultural, and (3) structural or institutional influences. For universities, a comparable set of three mechanisms explains why women's rank advancements are fewer, slower and lower than men's, notably ceilings, thresholds, and hurdles (Toren and Moore 1998). Ceilings indicate that due to individual factors women do not reach the highest ranks. Thresholds indicate that once women have passed a certain stage gender differences disappear, thus reflecting cultural factors. Hurdles refer to institutional barriers. These three perspectives best summarize the causes of vertical gender segregation. We consider them as complementing each other, not as mutually exclusive. We discuss examples of policy measures that illustrate each perspective.

\section{Individual perspective and related policies}

The central premise of the individual perspective is that men and women are basically different. Fagenson (1990) refers to this paradigm as the gender-centered perspective, in which women's underrepresentation at the higher levels in organizations is attributed to differences between men and women, mainly in psychological traits and socialization 
background, different work orientations or career choices (Billing and Alvesson 2000). In the early 1970s Schein $(1973,1975)$ demonstrated a relationship between sex role stereotyping and characteristics considered to be needed for management success. The stereotype of the relatively submissive, passive, non-rational character of women is considered to be contrary to the demands of top level positions (Billing and Alvesson 2000; Fagenson 1990; Ragins and Sundstrom 1989; Van Vianen and Fischer 2002). In addition to presumed differences in character, a discrepancy exists between the stereotyped conceptions of what women are like and of what upper level managerial jobs entail. This predisposition towards negativity leads to a devaluation of women's work accomplishments (Heilman 2001).

Expectations about the differences between men and women in personality and motivation which form the core of the individual perspective, lead to intervention strategies that support women. Training, coaching and mentoring women fit into this perspective. The intention of such programs has been described as measures to "fix" a lack of specific human and social capital in individual workers (Kalev et al. 2006). Bain and Cummings (2000) suggest that organizational features of universities should be modified to take into account gender-based differences in needs and lifestyle, like a greater appreciation for new research styles.

\section{Cultural perspective and related policies}

The cultural perspective suggests that the organizational context, which includes the organization's culture, history, ideology, and policies, is relevant in explaining women's limited success in attaining high level positions. Furthermore, organizations are located in societies, with particular cultural values, ideologies, societal and structural practices and stereotypes regarding appropriate roles and behaviors for men and women, which affect the processes in organizations (Fagenson 1990). Previous research (Broadbridge and Hearn 2008; Heilman 2001; Heilman et al. 1993; Ragins and Sundstrom 1989; Willemsen 2002) has demonstrated that, while management in organizations is represented as gender neutral, it often involves practices that are consistent with characteristics traditionally valued in men, stereotyping and a preference for men. Although explicit gender discrimination has been outlawed for many years, some of those studies have demonstrated that subtle discrimination still exists. Heilman (2001), for example, argues that gender bias in evaluations, performed by managers, is one of the causes of the scarcity of women at the upper levels of organizations. A study by Wennerås and Wold (2001) concerning the peer-review system of one of the main funding agencies for biomedical research revealed that "peer reviewers cannot judge scientific merit independent of gender". Studying salary data of one US university, Metcalfe and Slaughter (2008) found that women made significant gains in areas associated with the peer-reviewed knowledge, but that they do not gain as well in the resource rich academic areas associated with commercial research.

The occurrence of cultural constraints in the form of gender bias based on stereotypes is a well documented phenomenon and has even been acknowledged in legal procedures in the USA (Fiske et al. 1991). Policy measures that fit in with this perspective, like gender and diversity training, are intended to change the behavior of managers who are responsible for the hiring and selecting process or for promotions. Based on their literature overview Willemsen and Van Vianen (2008) recommend to provide training sessions for decision makers who are responsible for recruiting, selecting and promoting employees. Van den Brink et al. (2006) point out the importance of reflecting on the assumptions of talent scouts about the "excellent scientist" and their effects on the perceptions of men's 
and women's behavior and track records. They found a direct positive relationship between the number of women in selection committees and the chances of women to be appointed. $\mathrm{Ng}$ and Burke (2005) found, in an experimental study in which 113 MBA students participated, that women rated organizations with gender equality management more attractive as potential employers. These two latter studies suggest that some simple measures (e.g., having some women on selection committees, and clear communication of gender policies to applicants) may help diminish the cultural barriers mentioned in this section.

\section{Structural perspective and policies}

Factors related to the organization's hierarchy influence the entry and the promotion through the ranks (Fagenson 1990; Ragins and Sundstrom 1989). Kanter (1977), the most notable proponent of the structural approach, identified three variables as central explanatory dimensions: the structure of opportunity, the structure of power and the proportional distribution of men and women. Skewed groups, in which men are a majority, lead to treating women as "tokens": "they are often treated as representatives of their category, as symbols rather than individuals" (Kanter 1977, p. 208). This can put women at a disadvantage because of exclusion. Entry as well as promotion chances for women are negatively influenced by the restricted access to information about job openings. According to Bain and Cummings (2000) informal recruitment procedures at higher levels are one of the major areas where discrimination and prejudice towards women can creep into an organization. Apart from the structure of power, the overall career prospects in an organization determine its attractiveness. The institutional shape of the hierarchy bears directly on the likelihood of a starting employee to ascend the top ranks of an organization. Bain and Cummings (2000, p. 512) point out that the demography of universities can hinder career development of women especially: "The number of women in academe is so few and the rate of opening of new positions is so slow that simulation suggests, other things equal, it will take several decades for women to achieve parity with men at the top".

The structural perspective concerns the nature of organizational structures and the organization of work, rather than individuals or gender roles. Drawing on the intellectual biographies and career histories of 40 female scholars at 10 universities and colleges, formal organizational structures retain social control over the processes of feminist scholarship (Gumport 1990). Intervention policies based on this perspective adapt the recruitment and promotion procedure and try to retain junior talent, if possible in favor of women. For example, new types of appointments are introduced and financial incentives are offered to retain young promising (female) academics (Huisman et al. 2002). Kalev et al. (2006), using a longitudinal survey of employment practices, found that the best hope for remedying the inequality in attainment at work lies in practices that assign organizational responsibility for change. Their findings suggest that "the best hope [for remedying inequality in attainment at work] may lie in practices that assign organizational responsibility for change" (Kalev et al. 2006, p. 611). Based on the findings of two large studies of gender equity in Australian higher education, Probert (2005) states that measures that introduce transparency around workload allocations and promotion criteria within a meritocratic framework have had a significant impact in reducing gender discrimination.

The efficacy of policy measures

The effect of gender equality policies has hardly been evaluated. Most studies do not measure the quantitative result of gender equality initiatives in terms of the increase in the 
number of women, but instead study the reactions of men and women towards these policies (for example: Aberson 2007; Beaton and Tougas 2001; Dainty et al. 2001; Kossek and Zonia 1993), the perceptions of workplace diversity (for example: De Meuse and Hostager 2001; Hicks-Clarke and Iles 2000), or the perceptions of the effect of gender equality policy on women (for example: Camp et al. 1997). Studies that do consider quantitative effects are limited. Kalev et al. (2006) conducted an analysis of longitudinal data (1971-2002) on the workforce composition of US private sector establishments to assess changes in managerial composition after the adoption of equality practices. Programs were evaluated positively when a rise in the number of women in management was shown. They found that having affirmative action plans, equality committees and taskforces, equality managers and departments are the most effective means of increasing the proportions of women in private sector management. Jansen et al. (2001) studied the effect of several Human Resource practices by examining the changes of the share of women in the highest organizational levels during three time intervals. They could not demonstrate any positive effect of the personnel activities on women's share.

\section{Research objectives and methodology}

This study aims to investigate the efficacy of a gender equality policy. The objective of our empirical study is threefold.

1. Can gender equality policy measures applied in the academic sector be classified according to the three theoretical perspectives?

2. Do organizations apply gender equality policy measures randomly or can patterns be assessed in the portfolio of measures?

3. Do gender equality policy measures lead to improvements in proportion of females in higher job levels?

These research objectives have empirically been investigated for the 14 universities in the Netherlands. Between 2000 and 2007, all universities had implemented policy measures to enhance the position of female academics. We conducted a study to find answers to the three research objectives. A detailed report about this study is available in Dutch (Timmers 2007). This section first describes the universities and then details the data collection and the data analyses.

Cases: 14 universities in the Netherlands

The cases in this study are the 14 government-approved research universities in the Netherlands (see Table 1), which include nine general universities, four universities specializing in engineering and agriculture, and one Open University for distance learning at university level. The universities vary in size, with enrollments ranging from 6,000 to 30,000 students. The size of the academic staff varies from 500 up to 4,000 academics. In $2007,11 \%$ of full professors were female, one of the lowest proportions in Europe (VSNU 2008b). By contrast, the number of female students has been equal to that of male students for many years. Until recently, all academic jobs at the higher levels became available through a vacancy system only. Some universities now experiment with a tenure track system, where one can reach a higher job level, up to full professor, by promotion.

All 14 universities are subject to a Collective Labor Agreement, which is negotiated between the employers' organization (VSNU; Association of Universities in the 


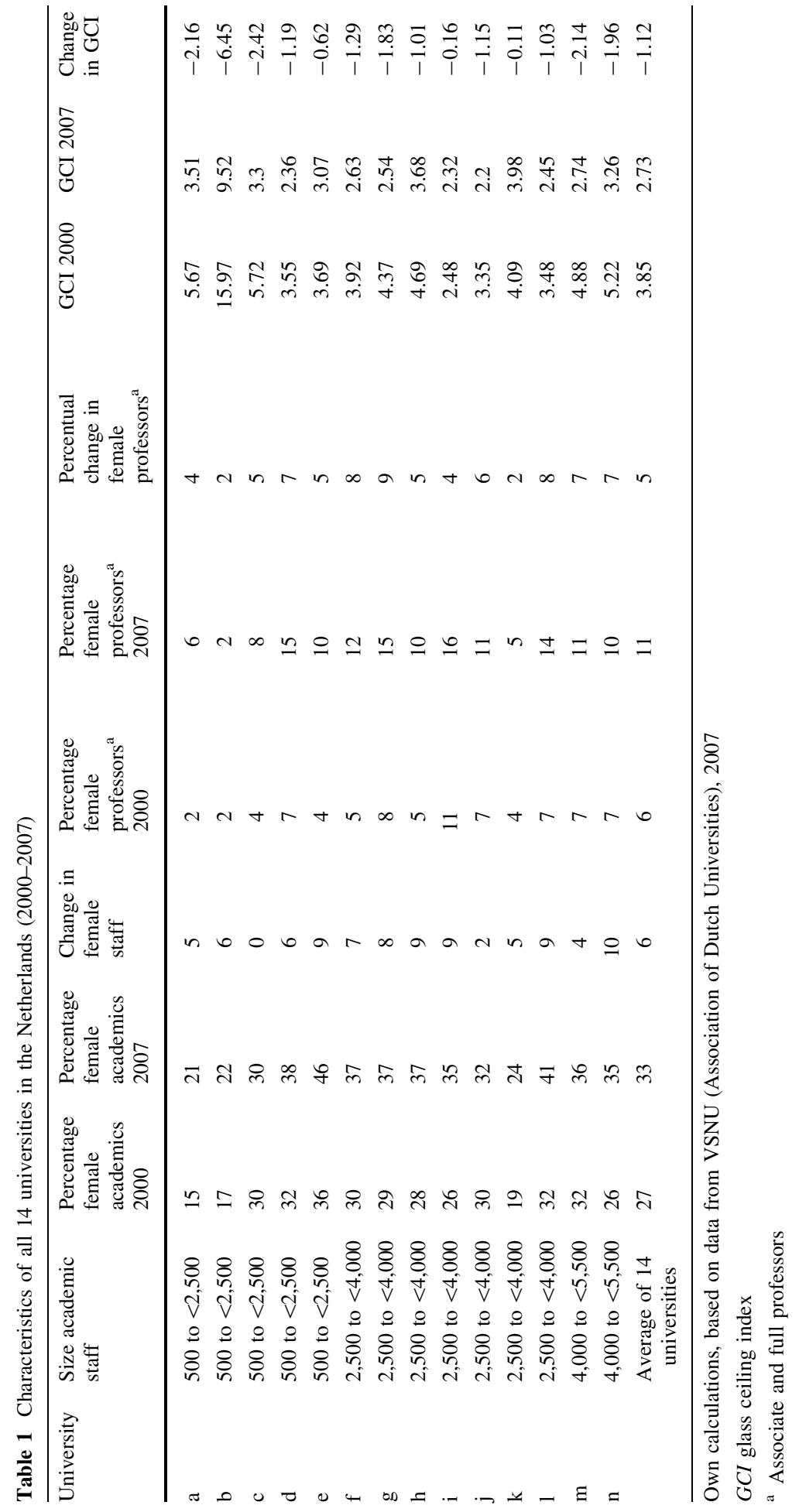


Netherlands) and three trade unions. In most years, the Agreement is renewed on an annual basis, but sometimes once in 2 or 3 years. All these universities pursue, according to article 6.3 in the Agreement 2007-2010, "an incentive policy aimed at women [...] and other employee groups in a disadvantaged or otherwise vulnerable position" (VSNU 2008a, p. 59). The Agreement explicitly indicates when and to which extent additional interpretations may be given at an institutional level (VSNU 2008b). The preceding seven Agreements, from 1997 onwards, contained similar clauses. According to these clauses universities are obliged to apply a gender equality policy, but they are allowed to implement those policy measures that suit their organization. No system is in place to monitor which initiatives have been adopted in which universities, or what their efficacy is.

\section{Data collection}

To explore the policy measures applied by the universities, the first step of data collection consisted of analyzing publicly available documents from primary and secondary sources. In these documents we searched for information related to the universities' gender equality policies for the period 2000-2007. Information on gender equality policies was solicited from sources like the Internet (universities' web pages), newspapers, books, articles in which the universities were featured, and annual reports available for all universities. Based on these documents a list of 29 different policy measures could be drafted, which according to the documents were applied in at least one university.

In a second step, we identified the staff members, mostly HR directors and policy makers, who were responsible for gender equality policy in their university. All were willing to cooperate in our study. We drafted a questionnaire to identify which of the 29 policy measures were applied between 2000 and 2007, to what extent, which were abandoned during this period or not considered at all in their university, and whether there were or had been any other policies in place during that period that were not mentioned in the list.

In the third step, at all 14 universities face-to-face interviews have been held with staff members responsible for gender equality policies at a central level. In eight universities we additionally contacted and interviewed one or more HR-staff members at a departmental level to gather information at that level. No one refused to participate and all completed the questionnaire before the interview took place or completed it during the interview. In total 27 HR staff members or policy makers were interviewed by the first author. The interviews conducted at the departmental level were equally distributed over relatively small (up to 2,500 academics staff); medium (2,500-3,500 academics); and large universities (over 3,500 academics). In the analyses we did not develop a multilevel approach, but we coded measures applied at departmental level differently from measures at university level. Each interview took approximately 2 hours and was tape-recorded. During the interviews the implementation of the 29 policy measures, the assumptions for applying them, and their efficacy were discussed.

Data analysis

To draft the portfolio of gender equality policy measures for every university, we had to reduce the initial number from 29 to 19 . Based on the questionnaires, the interviews and the policy reports we had to consider some measures that initially seemed distinct as one measure. For example, reporting the criteria for selecting academic staff, changing these criteria, reporting gender bias in the recruitment and selection procedure, and changing this 
procedure were combined into one measure "Review and adapt recruitment procedure". Other policy measures had to be dropped because they turned out not to be implemented in the universities, such as a recruitment policy to favor women even when they were just sufficiently qualified for a job. For some other measures, the interviewees could not provide any information about the implementation and therefore these measures had to be deleted too. For 19 policy measures we had sufficient information as to what extent they were applied in the universities. Combining the theoretical perspectives drafted in the previous section and the information derived from interviews, each measure was classified into the individual, cultural, or structural perspective. To be able to compose the portfolio, each measure was rated 0 (=not applied), 1 (=applied but not in all departments or not during the entire period under study), or 2 (=applied in the entire university during the entire period). For the 14 universities we could construct rankorders with regard to their gender equality policy measures in the three perspectives and in total.

We used two ways to investigate gender equality policy efficacy. Following Jansen et al. (2001) and Kalev et al. (2006), efficacy was operationalized as the change in the share of women. For all universities, we collected data on the change in the proportion of women among academic staff, all professors, full professors, PhD-students, and students each year between 2000 and 2007. This data was available from the Association of Universities in the Netherlands (VSNU). The independent variable was the ranking of the university on the application of policy measures.

The second way to investigate efficacy is related to the changes in the relative probability that women in comparison to men will reach a top position in their organization, for which we used an indicator called the Glass Ceiling Index, hereafter GCI (Zandvliet et al. 2002). The higher the value of the GCI, the thicker the glass ceiling, and the more difficult it is for women to move to a higher job level (European Commission 2006). The formula for the index we used is: GCI $=P_{1} / P_{2}$, where $P_{2}$ is the percentages of women among full and associate professors, and $P_{1}$ is the lower/middle job level, represented in the percentages of women among assistant professors, post-docs, researchers, lecturers and PhDstudents. The value can run from zero to infinity. A GCI score higher than 1 indicates a glass ceiling effect, showing that women are underrepresented at the highest job levels (European Commission 2006). As independent variable the ranking was used again.

\section{Results}

Classification of gender equality policy measures

The first objective of this study aimed to list the gender equality policy measures in the 14 universities in the Netherlands between 2000 and 2006 and to classify these measures according to the three theoretical perspectives. These perspectives represent a set of underlying assumptions about the causes of gender inequality in workplaces and, consequently, the kind of interventions recommended to bring about change. In total, 19 measures were identified, of which six were classified in the individual (I) perspective, five in the cultural (C) perspective and the remaining eight in the structural (S) perspective (see Table 2).

Measures were classified within the individual perspective when they aimed to remedy a presumed shortcoming of women compared to men. Mentoring and coaching of female staff (I2) counters social isolation. Moreover, this initiative is expected to teach women new skills and to enlarge their social networks. Additionally, a women's network (I4) can 


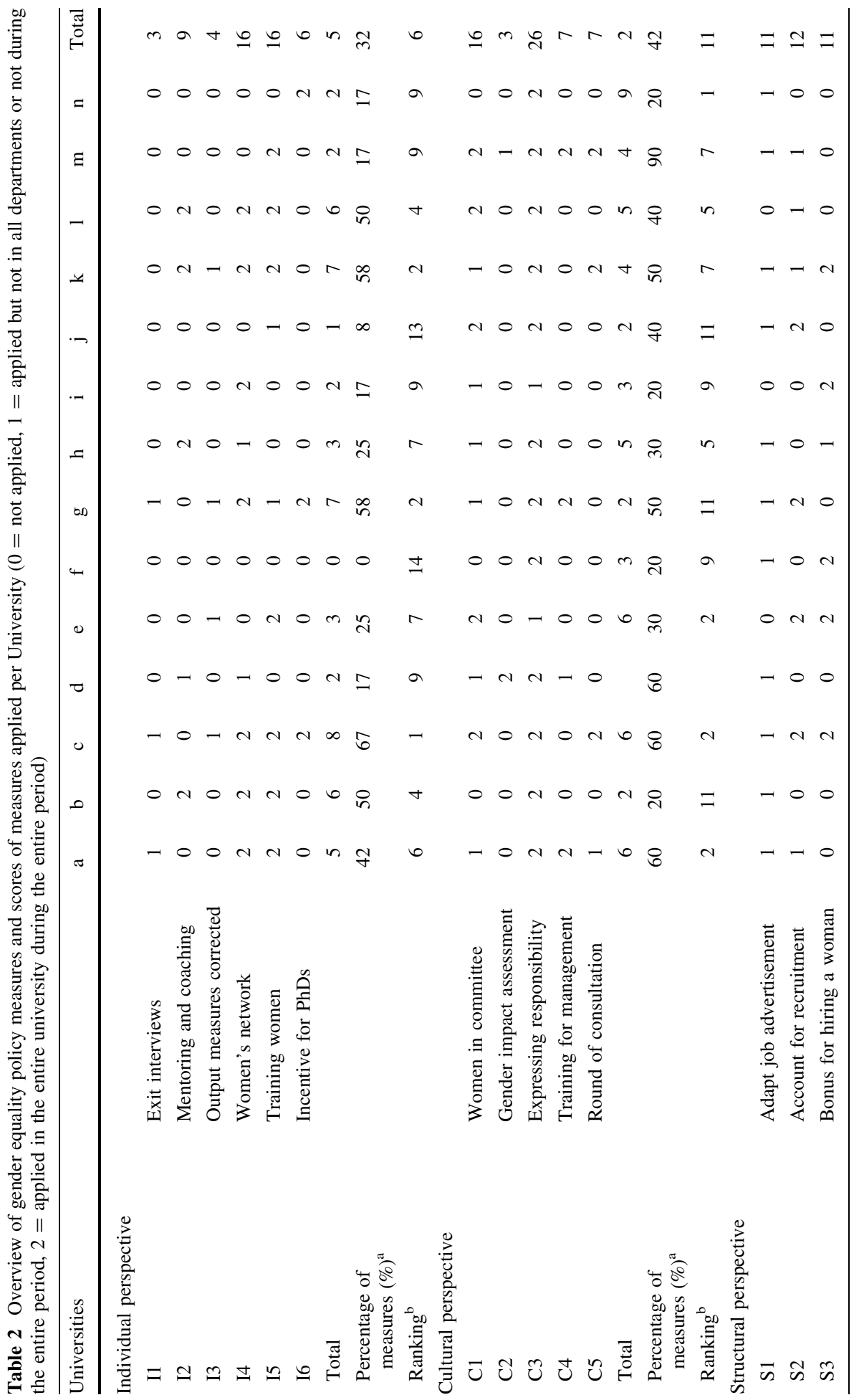




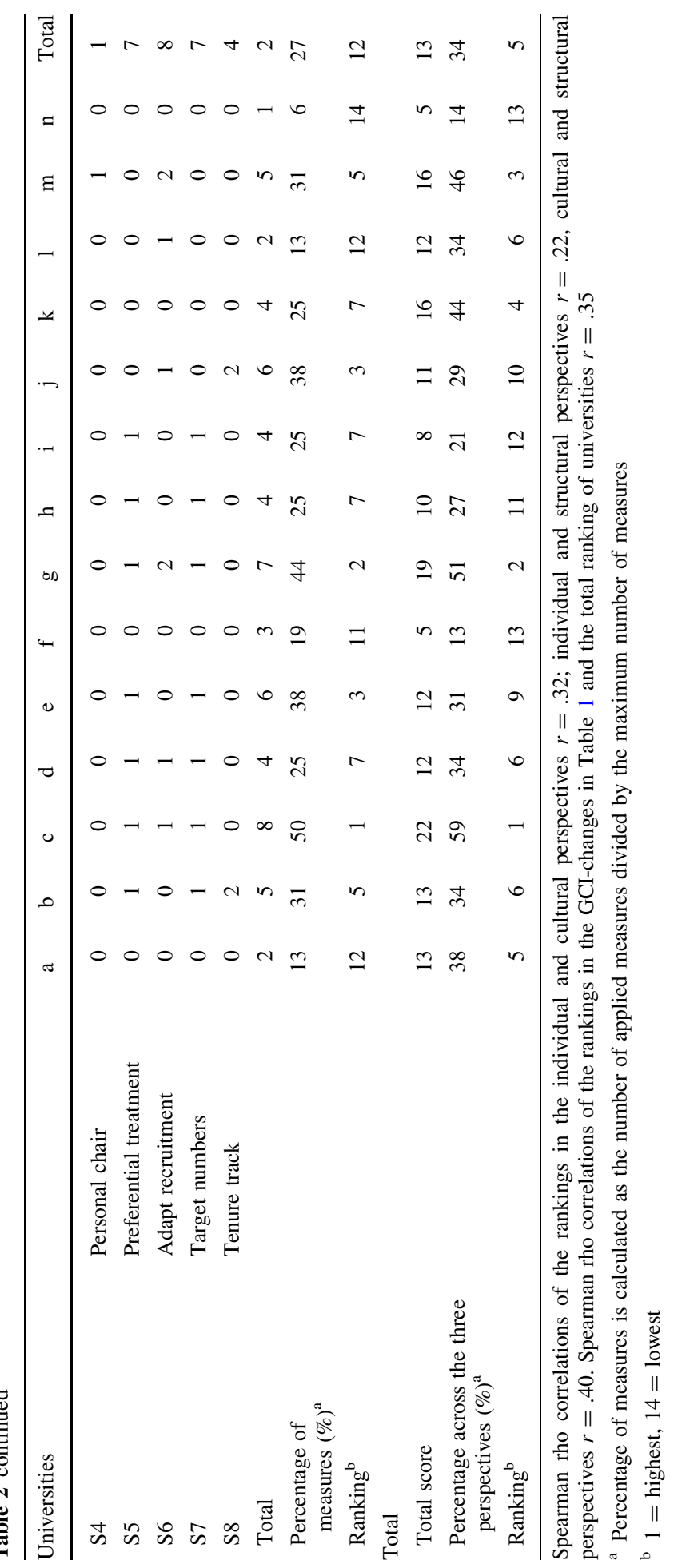


counter social isolation and act as an advisory task force. These networks are often financially supported by the universities. Training women (I5) provides them with the opportunity to improve their skills. By disbursing incentives to female PhD students or postdoctoral students (I6), they are provided with the opportunity to broaden their experience by working abroad. Employers apply such a policy measure to stimulate women to aim for a career in academia. To equally evaluate employees on their past performance, output is corrected to account for part-time work (I3). Finally, we included the exit interview measure (I1), when universities aimed to know whether, to what extent, and why women had quit the university. Note that policy measures allowing part-time working hours or offering pregnancy and maternity leave are not listed here, although these initiatives must be classified within the individual perspective. These measures are applied in all universities because Dutch law as well as the Collective Labor Agreement requires them to do so.

Measures were classified within the cultural perspective, if they focus on the responsibility for and support of applying a gender equality policy by managers and decision makers in particular and the decision making procedures in hiring and selection. To reduce gender stereotyping during those procedures and to increase the representation of women in decision making, employers can decide to always have one or more women in each hiring and selection committee (C1). A Gender Impact Assessment (C2) is a study on newly introduced personnel policies to rule out possible disadvantages for women. It tries to identify gender differences in future consequences of a current or proposed action which is related to both men and women. Other measures that embed accountability are employers request department managers to propagate responsibility and support for this policy (C3), they offer gender equality training for staff responsible for the hiring and selection procedures (C4), or they have a yearly round of consultation with deans to create awareness (C5).

Measures are part of the structural perspective, because they are expected to put pressure on decision makers to create equal opportunities for women to become an employee or to be promoted, and therefore to increase women's share at higher job levels. Reviewing and adapting job advertisements, for instance by explicitly requesting women to apply (S1), offering a bonus to a department when hiring a woman for a higher level job (S3), personal chairs for women professors only (S4), preferential treatment of women (S5), and tenure track offers (S8) all cater to increasing the chance of women to be employed at or be promoted to higher job levels. To ensure equality and formality in recruitment procedures employers can adapt hiring and selection procedures by making them more objective and gender neutral (S6). A hiring and selection committee that accounts for the recruitment of women to board of executives (S2) is expected to lead to a fair and transparent hiring and selection procedure. Setting target numbers (S7) brings about pressure on decision makers, because they are forced to increase the number of women in their departments.

\section{Patterns of policy measures across universities}

The second objective of this study aimed at assessing patterns across universities in the portfolio of policy measures implemented. Per university, the columns in Table 2 reveal the scores assigned to each measure and the partial scores assigned to each perspective. For the latter, no weights are applied. The Table shows the rankings of the 14 universities for each perspective and for the total.

As regards to the policy measures within to the individual perspective, support for a women's network (I4) and providing training for women (I5) are the most frequently 
applied. Both measures were applied in 9 out of 14 universities. By contrast, exit interviews (I1) are hardly applied and output measures (I3) are hardly corrected for staff in part-time positions. The latter is striking, taking into account that a substantial proportion of staff holds part-time jobs. When the numbers of applied measures are compared to the maximum number of measures, Table 2 reveals that University $c$ applies most measures, notably $67 \%$ of the maximum, whereas University $f$ does not apply any (0\%) measure at all.

As for the cultural perspective, expressing responsibility for applying a gender equality policy has the highest score (C3). It is applied in all 14 universities. All interviewees have stated that their university feels responsible for enhancing women's position. For various reasons, the universities strive at displaying their support. Interviewees stated that it was expected to lead to an advantage for new hires compared to other universities. Female candidates would be more attracted to a university that shows its responsibility for enhancing women's position. In addition, policy makers and HR directors expected more support and responsibility for this policy from decision makers at department level, when its importance is stated in formal policy documents. Table 2 also shows that a Gender Impact Assessment (C2) is hardly applied. Within the cultural perspective, University $m$ applies $90 \%$ of the maximum, whereas four universities rank lowest, because they apply only $20 \%$ of the maximum.

Concerning the structural perspective, accounting for the recruitment of women is applied most often (S2). Obliging departments to account for the recruitment of women to the Board of Executives leads to total compliance in four universities, while in another four universities only some departments follow this measure. By contrast, the personal chairs (S4) are hardly applied. As for this perspective, university $c$ ranks highest, as it implements $50 \%$ of the maximum. University $n$ ranks lowest, applying only $20 \%$ of the maximum.

In summary, Table 2 reveals a large variation in gender equality policy measures across the universities. The last row shows that two universities rank at the bottom with regard to the applied measures, expressed as the percentage of maximum measures. Universities $f$ and $n$ have almost no policies in place, as they applied only 13, respectively, $14 \%$ of the maximum measures. By contrast, universities $c$ and $g$ apply a broad range of measures with 59 , respectively, $51 \%$ of the maximum. When regressing the total ranking on the three perspectives rankings, the cultural perspective determines the total ranking most and the structural perspective least. This indicates that the more measures a university applied in the cultural perspective, the more likely this university also applied measures in the other two perspectives. The Spearman rho correlation of the rankings indicate that the measures in the cultural and the structural perspectives are highest correlated and the measures in the individual and the structural perspectives are lowest (Table 2 note). This indicates that the cultural and the structural measures are more often combined than the individual and the structural measures.

Efficacy of gender equality policy measures

The third objective of this study aimed at examining the efficacy of the university's gender equality policy. Both interviewees and policy reports often referred to future plans. The interviewees indicated that past experiences were hardly evaluated. According to the questionnaire, the universities had hardly evaluated the applied policy measures. In most cases policy makers only assumed that certain policy measures were effective or necessary. In the minority of cases where the university or the department evaluated a policy measure, efficacy was mostly assessed by describing increases in the share of women in the staff or by asking participants of policy measures for their opinion. 
As for the gender equality policy on the whole, the interviews sometimes revealed a discrepancy between official policy documents and the actual state of affairs. In these cases, one or more initiatives had been mentioned in policy documents, but were not yet put into practice at the time of the interview or were abandoned earlier than planned. In all 14 universities, interviewees could recall at least one and sometimes two or more plans, which were delayed. This was either due to poor planning or to a lack of support at departmental level. Many initiatives were of short duration and their implementation had not been coordinated consistently. In addition, the departments did not always comply with suggestions or even directives made by the Board of the university. For example, not a single interviewee at university level was entirely sure whether the departments had adapted the text of their job advertisements, although it was claimed to be a standard procedure. The same goes for preferential treatment of women.

Interviewees stated that most managers, policy makers, and full professors considered gender equality as a bureaucratic requirement. Applying measures had become a routine part of the paperwork of the academic hiring process. They also indicated that the gender equality policy measures were implemented because it was assumed that these would improve the university's ability to compete nationally and internationally for new hires. Universities also felt pressure from the government. During the past decade, universities have been stimulated to implement policy measures to increase the number of women in higher job levels. Nevertheless, most interviewees felt severely constrained in their ability to change the low share of women in higher job levels, given the gender composition of the pool of applicants for vacancies. One interviewee stated that applying a gender equality policy was no priority anymore in their university: “It doesn't fit our way of thinking, this policy is outdated". This interviewee was rather negative about gender equality policy, primarily because of the minor effects and the lack of support in the past. Nevertheless, most interviewees believed that in their university the gender balance at higher job levels, and therefore gender equality, would be a matter of time.

As the universities had hardly evaluated their gender equality measures, we used aggregated data on staff composition per university to assess the effects of the policy measures taken between 2000 and 2007. Table 1 shows the changes in the glass ceiling index (GCI), indicating that the GCI decreased in all universities and that the glass ceiling was less thick in 2007 than it was in 2000. To investigate the relationship between the GCI decrease and applying policy measures, we ranked the universities with regard to the decrease in GCI and the total number of measures applied (Table 2, last row). Spearman rho correlation of these two rankings is $r=.35$. Though this is not a very high correlation, it is sufficiently high to point towards the conclusion that universities who implemented gender equality policy measures faced a reduction of the glass ceiling.

To study the effects of the measures within the three perspectives, separate partial correlation analyses were performed for five hierarchical levels in universities (Table 3). We correlated the percentage of women among the student population, PhD-students, academic staff, professors, and full professors with each university's score on the three policy perspectives. These correlations were controlled for the percentage of women on that particular hierarchical level in 2000. Not surprisingly, the percentage female students is not significantly correlated to any of the gender equality policy perspectives. The percentage of female $\mathrm{PhD}$ students is negatively and significantly correlated with the cultural perspective. For both the students and the $\mathrm{PhD}$ students, it is plausible that the percentages of women are related to other factors than the university's gender policy. The percentage female academic staff is negatively correlated with two of the three policy perspectives. It is also negatively, though not significant, related to the third perspective. As the assistant 
Table 3 Partial correlation of the percentage of women in 2007, controlled for the percentage of women in 2000 , with the three gender equality perspectives for 14 universities

\begin{tabular}{llllll}
\hline Independent variables & $\begin{array}{l}\text { Full professors } \\
(N=14)\end{array}$ & $\begin{array}{l}\text { Professors }^{\mathrm{a}} \\
(N=14)\end{array}$ & $\begin{array}{l}\text { All staff } \\
(N=14)\end{array}$ & $\begin{array}{l}\text { PhD-students } \\
(N=14)\end{array}$ & $\begin{array}{l}\text { Students } \\
(N=13)^{\mathrm{b}}\end{array}$ \\
\hline Individual perspective & -.03 & .09 & -.21 & -.41 & .35 \\
Cultural perspective & .15 & $.52 * *$ & $-.60 *$ & $-.52 * *$ & .01 \\
Structural perspective & .18 & .20 & $-.60 *$ & -.17 & .12 \\
Total perspective & .13 & .38 & $-.60 *$ & $-.50 * *$ & .23
\end{tabular}

$* p<.05 ; * * p<.01$

a Associate and full professors

b Student population is not known for the Open University

professors are the largest group within this category, one may conclude that the university's gender equality policies obviously do not target this group. The percentage of female professors is positively and significantly correlated with one of the three perspectives, notably the cultural perspective. It is positively but not significantly related to the other two perspectives. Finally, the percentage of female full professors is positively but not significantly correlated to two out of three perspectives, and negatively and insignificantly with the third perspective.

In conclusion, whereas the interviewees reported skepticism and lack of evaluations of the applied policy measures, the relationships between policy measures and the reduction of the glass ceiling and between the policies in the cultural perspective and the increase in the proportion of females among professors reveal that the applied policy measures have been effective.

\section{Discussion}

The aim of this study was to examine the variation in gender equality policies and the efficacy of these policies. The empirical study, which investigated gender equality policies measures in all 14 universities in the Netherlands from 2000 to 2007, leads to five main insights.

Firstly, at the outset we identified three mechanisms explaining the low shares of women at higher job levels and therefore identifying the target of gender equality policies. These perspectives coincide with career hurdles that exist on an individual, cultural, and structural level. Differences between men and women in personality and motivation form the core of the individual perspective, leading to intervention strategies that support women. Policies related to the organizational context are associated with the cultural perspective. The structural perspective addresses the organization's hierarchy and policies try to influence the entry and the promotion through the ranks. We do not try to determine which perspective best describes the career threshold for women in universities, but instead we used the perspectives to classify the university's gender equality policy measures. This turned out to be a feasible approach.

Secondly, based on interview data and document analysis, we conclude that the 14 universities have implemented a total of 19 gender equality policy measures. Within the individual perspective, support for a women's network and training for women are the most frequently applied. Within the cultural perspective, expressing responsibility for 
applying a gender equality policy at department levels and women in selection committees are applied to a large extent. Within the structural perspective, accounting for the recruitment of women, adapting job advertisements, and bonuses for hiring women are applied frequently. By contrast, measures such as exit interviews, output measures adapted for part-time employees, Gender Impact Assessment and personal chairs are hardly applied. Using a mixed-mode approach of questionnaires, face-to-face interview data and document analysis turned out to be a viable approach for identifying, counting and classifying policy measures.

Thirdly, the mixed-mode approach revealed discrepancies between policies reported in documents and the information about these policies based on the questionnaires and the interviews. In all 14 universities, interviewees could recall at least one and sometimes two or more plans, which were postponed, not fully implemented, rather adopted as window dressing, used to improve morale than to improve women's careers. This turned out to be challenging for the classification and coding process of the policy measures. Additionally, our interviewees reported that implementing gender equality policies was a difficult process, because of skepticism and a lack of commitment among decision makers. Finally, implementing gender equality policies appeared to be a complex process, because of the loose relationship between the university and its departments. While most policies are decided at the university level, the cooperation of departments is urgently needed, but did not always comply. In our study, we kept the university level as the unit of analysis, and only controlled for partial implementation of policy measures in the coding of measures. In future research a framework should be utilized which is built up out of different hierarchical levels. This would lead to more insight in this complex policy implementation.

Fourthly, all 14 universities in our study applied gender equality policy measures, though with large variation. Expressed as the share of applied measures to the maximum number of measures, the universities ranged from 59 to $13 \%$. Universities apply relatively more often measures in the cultural perspective and less often those in the structural perspective. Additionally, using rank correlations it turned out that a university's ranking on the cultural perspective determined its total ranking most and the structural perspective did so least. Measures in the cultural and the structural perspectives are more often combined than the individual and the structural measures. From this we conclude that policies that address the organizational context are the most important features of the university's gender policies.

Fifthly, it turned out that the universities hardly had evaluated their gender equality policy measures. For investigating the efficacy of the policy measures, we had to rely on publicly available, aggregated data about the staff composition of the 14 universities over the period 2000-2007. The results indicate that the larger the number of gender equality policy measures, the larger the reduction of the glass ceiling in the university over the period 2000-2007. Furthermore, the increase in the percentage of women among professors is positively, strongly, and significantly correlated with the cultural perspective, and positively, but not strongly and not significantly correlated with the other two perspectives. The increase in the percentage of women among full professors is positively, but not strongly and not significantly correlated with the cultural and structural perspectives, and negatively and insignificantly with the individual perspective. Our study aimed at measures associated with increasing women's share in higher job levels. Not surprisingly, our findings indicate that the increase in the percentages of women among students, $\mathrm{PhD}$ students and academic staff are predominantly negatively related to the three perspectives. Yet, this may suggest that one domain of policy might go at the cost of other domains and this definitely needs further study. 
Acknowledgments This research was sponsored by a grant from SoFoKleS, the Dutch Social Fund for the Higher Education Labor Market to LNVH, the Dutch Network of Women Professors. A detailed report on this study in Dutch (Timmers 2007) was distributed to all cooperating universities and is available at www.sofokles.nl/html/projecten/vrouwenthema/best_practices.shtml. An overview of documents used for this analysis is presented in (Timmers 2007).

Open Access This article is distributed under the terms of the Creative Commons Attribution Noncommercial License which permits any noncommercial use, distribution, and reproduction in any medium, provided the original author(s) and source are credited.

\section{References}

Aberson, C. L. (2007). Diversity, merit, fairness, and discrimination beliefs as predictors of support for affirmative-action policy actions. Journal of Applied Social Psychology, 37(10), 2451-2474.

Altbach, P. G. (2004). Globalisation and the university: Myths and realities in an unequal world. Tertiairy Education and Management, 10, 3-25.

Bain, O., \& Cummings, W. (2000). Academe's glass ceiling: Societal, professional-organizational and industrial barriers to the career advancement of academic women. Comparative Education Review, 44(4), 493-514.

Beaton, A. M., \& Tougas, F. (2001). Reactions to affirmative action: Group membership and social justice. Social Justice Research, 14(1), 61-78.

Billing, Y. D., \& Alvesson, M. (2000). Questioning the notion of feminine leadership: A critical perspective on the gender labelling of leadership. Gender, Work and Organization, 7(3), 144-157.

Boeckmann, R. J., \& Feather, N. T. (2007). Gender, discrimination beliefs, group-based guilt, and responses to affirmative action for Australian women. Psychology of Women Quarterly, 31, 290-304.

Broadbridge, A., \& Hearn, J. (2008). Gender and management: New directions in research and continuing patterns in practice. British Journal of Management, 19, 38-49.

Camp, S. D., Steiger, T. L., Wright, K. N., Saylor, W. G., \& Gilman, E. (1997). Affirmative action and the "level playing field": Comparing perceptions of own and minority job advancement opportunities. The Prison Journal, 77(3), 313-334.

European Commission. (2006). She Figures 2006. Women and science. Statistics and indicators. Brussels: European Commission, Community Research.

European Commission. (2008). The life of women and men in Europe. A statistical portrait (2008 edition ed.). Luxembourg: European Communities.

Dainty, A. R. J., Bagilhole, B. M., \& Neale, R. H. (2001). Male and female perspectives on equality measures for the UK construction sector. Women in Management Review, 16(6), 297-304.

De Meuse, K. P., \& Hostager, T. D. (2001). Developing an instrument for measuring attitudes toward and perceptions of workplace diversity: An initial report. Human Resource Development Quarterly, 12(1), $33-51$.

Enders, J. (2001). Academic staff in Europe: Changing context and conditions. Westport: Greenwood Publishing Group.

Fagenson, E. A. (1990). At the heart of women in management research: Theoretical and methodological approaches and their biases. Journal of Business Ethics, 9, 267-274.

Fiske, S. T., Bersoff, D. N., Borgida, E., Deaux, K., \& Heilman, M. E. (1991). Social science research on trial. Use of sex stereotyping research in Price Waterhouse v. Hopkins. American Psychologist, 46(10), 1049-1060.

Gumport, Patricia. J. (1990). Feminist scholarship as a vocation. Higher Education, 20(3), 231-243.

Heilman, M. E. (2001). Description and prescription: How gender stereotypes prevent women's ascent up the organizational ladder. Journal of Social Issues, 57(4), 657-674.

Heilman, M. E., Kaplow, S. R., Amato, M. A. G., \& Stathatos, P. (1993). When similarity is a liability: Effects of sex-based preferential selection on reactions to like-sex and different-sex others. Journal of Applied Psychology, 78(6), 917-927.

Hicks-Clarke, D., \& Iles, P. (2000). Climate for diversity and its effects on career and organisational attitudes and perceptions. Personnel Review, 29(3), 324-345.

Huisman, J., De Weert, E., \& Bartelse, J. (2002). Academic careers from a European perspective. The declining desirability of the faculty position. The Journal of Higher Education, 73(1), 141-160.

Jansen, P. G. W., Van der Velde, M. E. G., \& Telting, I. A. (2001). The effectiveness of human resource practices on advancing men's and women's ranks. Journal of Management Development, 20(4), 318-330. 
Kalev, A., Kelly, E., \& Dobbin, F. (2006). Best practices or best guesses? Assessing the efficacy of corporate affirmative action and diversity policies. American Sociological Review, 71(4), 589-617.

Kanter, R. M. (1977). Men and women of the corporation. New York: Basic Books.

Kossek, E. E., \& Zonia, S. C. (1993). Assessing diversity climate: A filed study of reactions to employer efforts to promoting diversity. Journal of Organizational Behavior, 14(1), 61-81.

Metcalfe, A., \& Slaughter, S. (2008). The differential effects of academic capitalism on women in the academy. In J. Glazer-Raymo (Ed.), Unfinished business: Women, gender and the new challenges of higher education. Baltimore: Johns Hopkins University Press.

Ng, E. S. W., \& Burke, R. J. (2005). Person-organization fit and the war for talent: Does diversity management make a difference? The International Journal of Human Resource Management, 16(7), 11951210.

NU, V. S. (2008). Collective labour agreement Dutch Universities, 1 September 2007 to 1 March 2010. The Hague: Association of Universities in the Netherlands.

OECD. (2008). Dataset: Students enrolled by age: Organisation for economic co-operation and development.

Probert, B. (2005). 'I just couldn't fit it in': Gender and unequal outcomes in academic careers. Gender, Work and Organization, 12(1), 50-72.

Ragins, B. R., \& Sundstrom, E. (1989). Gender and power in organizations: A longitudinal perspective. Psychological Bulletin, 105(1), 51-88.

Schein, V. E. (1973). The relationship between sex role stereotypes and requisite management characteristics. Journal of Applied Psychology, 57, 95-100.

Schein, V. E. (1975). The relationship between sex role stereotypes and requisite characteristics among female managers. Journal of Applied Psychology, 60, 340-344.

Timmers, T. M. (2007). Op zoek naar best practices. Een onderzoek naar de effectiviteit van emancipatiebeleid in de periode 2000-2007 aan de 14 Nederlandse universiteiten. (Looking for best practices. A study on the effectiveness of gender equality policy from 2000 on to 2007 in 14 Dutch universities). Rotterdam: SoFoKleS, LNVH.

Toren, N., \& Moore, D. (1998). The academic "hurdle race": A case study. Higher Education, 35(3), 267283.

Van den Brink, M., Brouns, M., \& Waslander, S. (2006). Does excellence have a gender?: A national research study on recruitment and selection procedures for professional appointments in the Netherlands. Employee Relations, 28(6), 523-539.

Van Vianen, A. E. M., \& Fischer, A. H. (2002). Illuminating the glass ceiling: The role of organizational culture preferences. Journal of Occupational and Organizational Psychology, 75, 315-337.

VSNU. (2008b). WOPI 2007, measure date 31 December: Association of Universities in the Netherlands.

Wennerås, C., \& Wold, A. (2001). Nepotism and sexism in peer-review. In M. Wyer, M. Barbercheck, D. Giesman, H. Orun Ozturk, \& M. Wayne (Eds.), Women, sience and technology: A reader in feminist science studies (pp. 46-52). New York: Routledge.

West, M. S., \& Curtis, J. W. (2006). AAUP faculty gender equity indicators 2006. Washington: American Association of University Professors.

Willemsen, T. M. (2002). Gender typing of the successful manager-a stereotype reconsidered. Sex Roles, 46(11/12), 385-391.

Willemsen, T. M., \& Van Vianen, A. E. M. (2008). Gender issues in work and organizations. In L. Steg, A. P. Buunk, \& T. Rothengatter (Eds.), Applied social psychology: Understanding and managing social problems (pp. 206-225). Cambridge, UK: Cambridge University Press.

Zandvliet, K., Blanken, R., Kroes, H., \& Van Nes, P. (2002). Vrouwen in hogere functies. Ontwikkeling benchmark. (Women on higher level ranks. Development of a benchmark). Rotterdam: SEOR BV, Ministerie van Sociale Zaken en Werkgelegenheid. (Ministry of Social Affairs and Employment). 